\title{
DIFFERENT LEVEL OF LEARNED-HELPLESSNESS AMONG HIGH SCHOOL STUDENTS WITH LOWER GRADE AND HIGHER GRADE IN SALATIGA INDONESIA
}

\author{
Berta Esti Ari Prasetya \\ Faculty of Psychology \\ Satya Wacana Christian University \\ email: bertaprasetya@gmail.com
}

\begin{abstract}
This research aimed to investigate whether there is any significant difference in the tendency of experiencing learned-helplessness between high school students with lower grade and higher grade in Salatiga, Indonesia. Survey method was used in collecting the data, utilizing Perceived Influence Questionnaire (Holt, 1980) as the instrument of measurement. 317 participants were involved, consisted of 190 of higher grade students and 127 of lower grade students. Mann-Whitney U was used to analyse the data, considering that the data were not normally distributed. This test result showed that there was a significant difference between high school students with higher grade and lower grade (the Mann-Whitney U coefficient of 10,644, with $z$ value of $-1795, p<0.05$ ( $p=0036$, 1-tailed)), with students of lower grade tend to be more prone to experience learned-helplessness. Additional results from their subjective perception on their achievement were also discussed and so were the implications of the study.
\end{abstract}

Keyword: Learned-helplessness, lower grade \& higher grade.

\section{INTRODUCTION}

For every nation, students are invaluable assets who are expected to be the backbone of the continuity of its national life. The future of a nation can be predicted from the quality of its students, because it is in their hands lies all the hope for innovation and the improvement to make a better nation. Considering that, improving the quality of the students should become an important agenda for governments and every level of society.

It has been long that Indonesia is strugling with the problem in academic achievement of its students, as it was recorded that the average of Indonesia's academic achievement ranked very low compared to its neighbouring countries, especially in areal of reading comprehension (Sundiawan, 2006). Inability to grasp the essence of reading may in turn resulted in lower academic performance. Like what was reflected in the result of national exam, most of the results were somewhat dissapointing (Jalil, Suara Merdeka, March 6th, 2006). It is therefore, some schools start to give additional hours to their students to have a programme to prepare for the national exam. But in some occation this effort did not turn out like once was expected. If the students eager to study harder, there are some possibility that they may improve their performance. But if they fall to being learned-helplessness, then the effort of the school may become futile, for the student do not even want to try to study harder to improve their performance because they do not think that their effort will result in the improvement of their performance, after several failures that they faced.

Having lower grade in school, means that students had experienced failure after failure. This repeating failures according to Seligman (1991) may lead to the condition of learned-helplessness, that characterized by being passive, merely to 
avoid failure, with no real desire to get knowledge. The phenomenon of students cheating during national examination, rather than study, as a simple and easier way try to "not fail", can be pinpointed as one indication of learnhelplessness among the students. They choose to be pasive, rather than to work harder to improve their knowledge. Some students often feel desperate before starting to study for their exam, and believe that the grade that they got are only given by chance.

According to Scales and Roehlkepartain (2003) and Rusyan et al. (In Pujianingrum, 2003), motivation is very important to achieve better. But people who experience learned-helplessness is afraid to try. This may lead to another low grade, and make him/her become even more convinced that they are incapable, and that there is no use to study even harder, because the result is the same. At the opposite, those who has higher grade, they may see that their hard work is paid off, then they work even harder and excel even more.

Given the considerations above, this study intend to examine whether there is a difference in the level of learned-helplessness among the high school students based on their academic achievements. The other condition will also be investigated in order to conduct a programme to overcome learned-helplessness among high school students so that they may improve their accademic performance. This study is considered as the first phase of how to conduct an effective programme to overcome learned-helplessness among students. In the next phase of the study, the programme can be created and the effectivity of the programme can also be evaluated. The town of of Salatiga is chosen to be the area of study considering that this is a small town that needs to be given more attention compared to other bigger town or cities in Indonesia. The study also asked open-ended questions to find out things that related to the condition of learned-helplessness among highschool students in Salatiga, Indonesia.

\section{Problem formulation}

Based on the above mentioned, this research question is:
"Is there any significant difference in the level of learned-helplessness among high schoool students with lower grade and students with higher grade?"

\section{REVIEW OF LITERATURES}

\section{Learned Helplessness}

In general, learned-helplessness is a phenomenon where an organism learns or concludes, after a series of experiments/exposure, that he has no control over the results (outcomes) of an event (Barber, 1985). The organism is unable to see any connection between his efforts and changes in the environment or achieving goals. This produces the effect of passive conditions and reduced its ability to withstand a task/ thing (Maeir \& Seligman, 1967).

The condition of learned-helplessness can be experienced by individuals in various situations, including in educational setting. In education setting, students may also have learnedhelplessness resulting from exposure to the successive failures in school.

\section{Factors affecting Learned-helplessnes}

Research done by Barber (1985) found that one important characteristic of experiencing learned-helplessness is a condition that the individual feels unable to control (not in control) of the results (outcomes) from the effects of his behavior. Apart from that, Barber also found that the subjective sense of failure will affect whether an individual will experience learned-helplessness or not. If the failure is regarded as essential for individuals, learned-helplessness may present. If the failure is subjectively not regarded as important for the individual, the individual would not experience learned-helplessness.

Research done by Peterson and Seligman (1984) found that how individuals interpret an event will determine whether or not he/she experience learned-helplessness. Individuals who have a negative explanatory style are likely to see negative events as permanent (eg: conditions exist for ever), personal (for example: I was stupid), and are pervasive (eg: in all areas I can not be 
what is right), will tend to experience learnedhelplessness.

Cullen and Boersma (1982) found that learned-helplessness influenced by the actions of parents and teachers towards the students. Parents or teachers who repeatedly tell the children that failure is caused by incompetence and not because they are less trying to achieve better, would tend to cause feelings of helplessness in children.

\section{The characteristics of individuals who experienced Learned-helplessness}

In addition, individual also has a habit to not want to "try", as the effect of successive failures s/he experienced before. His/her behavior is considered as a waste of time trying, because they believe that they will not succeed anyway.

Individuals who have learned-helplessness tend to avoid failure rather than trying to find knowledge (Titscher \& Kubinger, 2008). When faced with problems, students who experienced learned-helplessness tend to choose easier question because he is hopelessness, rather than choosing a more difficult problem that can actually bring in new knowledge.

Dweck (2000) explains that individuals who are helpless, when they are faced with failure, they tend to make a permanent internal attribution. They give attribution that the failure is caused by his personal disability, thus allowing the emergence of negative emotions, the decline in performance and decline of self-esteem. At the opposite, individuals who have a tendency of mastery oriented are usually more focused on themselves to find solutions rather than try to find excuses for failure he make. In previous studies Dweck and Repucci (1972) compared those who did not experience helplessness (mastery orientation) are more likely to see the failure as internal attribution that are not permanent, ie assessing the failure occurred because of lack of effort.

\section{Definition of Academic Achievement}

Learning occurs as the mutual interaction between the learner and everything that exists in the environment. For learning to happen, it needs the willingness of the learners to open themselves to the stimuli outside himself. And it can be said, the success of learning will also be determined by the extent of the enthusiasm he showed to interact with its environment.

The result of learning may not be observable by other, but because it is only stored within the individual and not yet actualized. However, without an actual measurement a research will be impossible to be done. It is therefore in this study, academic achievement is defined in terms of the achievements that are already actualized. Considering the importance of having a definition of academic achievement as something that can be measured, then the definition of Thantawi (1997) may be used as a reference for defining the academic achievement. That is: a sign or symbol of success had been achieved from the effort to learn, which is usually expressed in grades, numbers or letters, where the sign represents the actual ability in the field of knowledge and skills. Anwar (1996) adds that learning achievement can be expressed in value or grade report cards (IP), graduation rates, and predicate the success obtained from the measurements of academic achievement.

In this study, academic achievement is divided into two groups, which are students with higher grade and students with lower grade. Students with higher grades are those who have become the 5 upper rank in every class and have the grade of more than 8 (scale 0-10). Students with lower grade are those who were the 5 lowest grade in his/her class with the grade maximum of 6 (scale 0-10).

\section{Learned-helplessness level differences between Higher Education Student Achievement and Students with Low Learning Achievement}

Several studies in education have found the importance of reinforcement to improve behavior. Nevertheless, various studies have also prove that there are some students who can not see the effects of reinforcement because they are unable to see the relationship between the response he did with 
the results or effects of such behavior (Blair, 1972), a condition in which was referred by Seligman (1991) as a condition of learned-helplessness.

Review of Canino (1981) found that the learned-helplessness effects can include the effects of cognitive, motivational, and emotional, which include delays in learning, the passivity of individual's behavioral and a growing physiological condition of distress.

Research Hiroto and Seligman (1975) among students found that when faced with insoluble problems and painful sounds that could not be controlled, the students became less motivated, effort that was usually done decreased drastically and their attitude about their intellectual capability dercreased, and so did their self-esteem. Individuals also showed a decline in intellectual performance, thus failing to perform tasks that previously capable of doing.

Individuals who experience learnedhelplessness due to repeated failures in the past will take the erroneous conclusion that they were not able to improve their performance (Stipek, 1988). In conjunction with academic tasks, the individual who experience learned-helplessness tend to feel that he/she is incapable to do more than what they have done, so that they are even left behind by other students.

Ramirez, Maldonado, and Martos (1992) found that children who experience learnedhelplessness usually fail their academic subjects, and less motivated by intrinsic motivation compared to others. They tend to be more passive and less interested to try to improve their academic performance.

Another effect of learned-helplessness is a loss of confidence, inability to resolve the problem, attention that is less focused and feeling of hopeless. Individuals who experience learnedhelplessness also tend to easily give up when faced with a variety of academic problems (Shields, 1997). With this condition, it is possible that the students will even more left behind in their academic achievement compared to other students.

\section{Research Hypothesis}

There is significant differences in the tendency of learned-helplessness among groups of students with higher grade and students with lower grade. Students who have lower grade tend to experience learned-helplessness more than students who have higher grade.

\section{METHOD}

\section{Method and result}

The mehod used in this study was a quantitative survey method. In this case, the collected data based on subjective evaluations of the participants in the form of self-report. The questionnaire used for this study is PIQ (Perceived Influence Questionnaire) by Holt (1980). After the validity and reliability test, 14 items were retained for data collection.

The data were collected from 4 schools in Salatiga for those who have higher grade (who were the 5 top rank in every class) and those who have lower grade (who were 5 lowest rank in class). Four hundred (400) questionnaires were distributed, and 371 were returned, but it was only 317 that were able to be analyzed due to the imcomplete data that was reported by the participants. The higher grade group were consist of 190 participants and the lower grade group were consist of 127 participants. When the normality of the data was tested, it was found that the data was not normally distributed, therefore the test of Mann-Whitney U test was used to examine differences between the two groups.

\section{Results}

The result of descriptive analyses showed that the mean of the group of higher grade was 5.88 with SD 2.15. Meanwhile the mean of group with lower grade was 6.27 with SD 2.04.

The test of Mann-Whitney U was implimented and resulted in coefficient of 10.644 with $z$ values of $-1795 \mathrm{z}$ and $\mathrm{p}<0.05$ ( $\mathrm{p}=0036,1$-tailed). 


\section{Additional Analysis Results from additional and open-ended questions:}

Additional questions submitted to the subject turned out to produce some findings that can be reported.

\section{Descriptive Analysis of Perception Regarding individual's success}

Students' achievement that was reported on the student report card (either higher grade or lower grade) is an objective fact about the results of students' studies. However, each student also has the perception on his/her success on his/her studies. In open-ended questions part of the questionnaire, the subjects were asked to judge whether he felt as an academically successful students or not and who support them to feel that way.

In the group of lower grade students, this question is answered by 41 subjects, of which 29 subjects claimed to feel like a failure in academics (70.7\%), while 12 people felt themselves successful in academics (29.3\%).

In the group of higher grade students, this question is answered by 54 subjects, of which three subjects $(5.6 \%)$ declared themselves felt as a failure in academics, while 51 subjects $(94.4 \%)$ felt successful in academic achievement.

\section{Significant others}

The participants were asked who is influential on their perception either as a succesul or unsuccessful person in their academic achievement. Among the higher grade group, 40,9 percent stated that the parents were the one who play a role in making them feel successful in academics, followed 19,1 percent stated that they get support from teachers $(19.1 \%)$, while 9.1 percent stated that they get support from friends. Among the group of lower grade, the highest percentage which is 41 percent responded that no one supports them to feel successful/unseccesful, followed by those who reported that they get support from friends at 15.4 percent. Meanwhile, only 2.9 percent stated that they gain support from parents and teachers.

The results of the analysis of differences in learned-helplessness based on subjective perceptions of academic success

The results of descriptive analysis of the tendency to experience learned-helplessness of individuals showed that for groups who perceive themselves as unsuccessful, the mean is at 7.21 with SD 1.88, with a minimum score of 3 and a maximum score of 11 . As for groups that perceive themselves as successful, the mean is at 6.30 with a SD of 1.80, with a minimum score of 2 and maximum score 10 .

To examine differences in learnedhelplessness trend in between those who perceived themselves as successfull and unsuccessful the Mann-Whitney U was used to analyse the data. The analysis showed that the coefficient for the Mann-Whitney U z 764000 and the value of 1951 with $\mathrm{p}<0.05$ ( $\mathrm{p}=0.25,1$-tailed $)$.

\section{DISCUSSIONAND IMPLICATION OF THE STUDY}

This study found that there was a significant difference in the tendency to experience learnedhelplessness among groups of students with higher grade and those with lower grade (values of $\mathrm{z}$ $1795 \mathrm{z}$ and $\mathrm{p}<0.05$ ( $\mathrm{p}=0036,1$-tailed)). The tendency to experience learned-helplessness was significantly higher among group of lower grade than group of higher grade.

The result of the research was in line with the results of research developed by Hiroto and Seligman (1975) that after repeating failures and feel being not in control of the situation, they become less motivated, their effort was decrease drastically, and her attitude about the intellectual ability became very negative. They also showed that their intelectual performance was decline, thus failing to perform tasks previously capable of doing, and the decline of self-esteem as well.

Still in line with the above conditions, the research done by Stipek (1988) found that repeated failure in the past will make the individual take a 
wrong conclusion that they were not able to improve their performance. In conjunction with academic tasks, individuals who experience learned-helplessness because of various failures in the execution of academic work in the past would feel unable to do more, so that they were even more left behind by the other students. Meanwhile, earlier studies also found that conditions of learned-helplessness, in turn, also results in lower academic achievement of individuals. As found by Ramirez et al. (1992) that children who experience learned-helplessness often experienced failure in academic subjects. In line with these findings, the study Shield (1997) also found that individuals who experience learned-helplessness tend to easily give up when faced with a variety of academic problems, which led also to the low academic achievement. Research done by Razeen (2004) among students in Malaysia have also found a significant correlation between the tendency of learnedhelplessness with implications for their lower accademic achievement.

Descriptive analysis of the results of this study found none of the group (either lower grade group and higher grade group) has very high propensity to experience learned-helplessness. In the group of higher grade students, 12.2 percent of them were found to have high tendency of being learned helplessness, while among lower grade group there were 13.6 percent were found to have tendency of being learned-helplessness. Most individuals were rank modest in their thendency of learned helplessness. This result that nobody has a high tendency, and only about $12-13$ percent of high tendency of being learned-helplessness either from higher grade group or from lower grade group seems in line with the subjects' answer to the question whether they believe that that the failure can be avoided. Among students who answered this question, there is only one person who claimed that the failure can not be avoided, while the rest of other students believe that failure is evitable. When they were asked their reason, even students who were included in the group of lower grade stated that they were actually capable of doing better, able to cope with their failures if they want to try harder, but they said that they were just lazy to do so. From this result seems that there is still a belief or optimism from students about their ability to cope with their failures, provided they are willing. But it seems that it is the self-discipline to work harder that needs to be improved. In relation to the question what is the best programme to improve their accademic performance, the programme must be able to help students to pinpoint what cause their laziness, and how to build more self-discipline. At the same time they need to check if they actually unconsciously believe that their effort will be futile, it is therefore they are lazy to work harder.

The study also tried to see if there is consistency between their learning achievements objectively (from the rank and value of report cards), with their own subjective perceptions about their success. This study found that among students who belongs to a group of higher grade, there are still 5.6 percent who considered themselves to fail, while the 94.4 percent rate themselves as succesful student in terms of academic achivement. In the qualitative question, those who perceive themselves as a failure stated that they felt as a failure because they can not reach their target to achieve a certain ranking or grade.

Meanwhile, in a group of students who have lower grade, 70.7 percent rated themselves as individuals who fail academically and there are 29.3 percent of them who feel that they are successful in terms of academic. This can be interpreted by at least two ways. The first, this might make the students do not experience feelings of inferiority because they still feel as individuals who are successful. Which can be considered as a positive side of this statement. However, this could also be interpreted as they are less sensitive to see the fact that they need some improvement. If individuals do not see that their old way of study is actually not effective to bring them to have better achievement, then there would be no effort to change their way of study to be more effective. The implication of this finding 
for the improvement programme, is that the programme has to include how to asses themselves accurately, and see in what way they can be more effective to improve their academic performance. The programme also need to pay more attention to those who keep on feeling unsuccessfull even that they are in group of higher achiver, so that they can learn how to appreciate their acomplishment rather than keep on feeling unsuccessfull even that they are successfull already.

The additional analyses also found that there was a significat difference in their level of learnedhelplessness among group who perceived themselves as individuals who succeed academically and those who perceived themselves as not successful in their academic achivement (The test used was a Mann-Whitney U, with a value of $\mathrm{z}=-1941, \mathrm{p}<0.05)$. The results are in line with research conducted by the Banks \& Woolfsoon (2008), that individuals who rate themselves as having lower achievement tended to explain his failure with the attribution of more internal / stable (eg, I failed because I was stupid), and more feel helpless in controlling the things that make him fail, than those who rate themselves as people who succeed academically (high achievement). Or in other words, individuals who assess themselves as people who fail, have a tendency to have learned-helplessness higher than those who perceived themselves as successfull individuals.

When they were asked who is their significant other who make them feel the way they feel either successfull or unsuccessfull, among higher grade students: 40.9 percent of them reported that it is their parents who make them feel the way they do, followed by 19.1 percent of the participants stated that it was their teacher, while 9.1percent stated it was their close friends. This opposite configuration is found among the lower grade group. Forty-one percent $(41 \%)$ of them stated that no one supports them to feel they way they do, followed by 15.4 percent stated that it was their friends who make them feel the way they do. Meanwhile, only 2.9 percent the states that it was their parents and teachers who make them feel the way they do.

Looking at this configuration, we can see that among higher grade group, they tend to put a figure of authority such as parents and teachers who are significant in making the way they feel about their academic achievements. While among lower grade, tend to feel that no one is significant in influencing their feeling of being successfull or unsuccessfull. They also point their peers as those who make them feel successful or unsuccessful. Meanwhile, the authority figures such as teachers and parents were placed in positions that are not significant in determining the feeling or success that they feel. This result give us idea of who can be invited in the programme to help those students of higher grade and lower grade in overcoming their feelings of learned-helplessness.

\section{CONCLUSION}

This study found that there was a significant difference in the tendency to experience learnedhelplessness among groups of students with higher grade and those with lower grade (values of $\mathrm{z}$ $1795 \mathrm{z}$ and $\mathrm{p}<0.05$ ( $\mathrm{p}=0036,1$-tailed). The tendency to experience learned-helplessness was significantly higher among group of lower grade than group of higher grade. Even that those students in lower grade have a higher level of learned-helplessness, most of them still believe that failure is evitable if they are willing to work harder. They believe that their lower scores resulted from their laziness and lack of discipline in study, but they can not do anything about it.

The additional analyses also found that there was a significat difference in their level of learnedhelplessness among group who perceived themselves as individuals who succeed academically and those who perceived themselves as not successful in their academic achivement (The test used was a Mann-Whitney $\mathrm{U}$, with a value of $\mathrm{z}=-1941, \mathrm{p}$ $<0.05)$. Or in other words, individuals who assess themselves as people who fail, have a tendency to have learned-helplessness higher than those who perceived themselves as successfull individuals. 
Among higher grade group, they tend to put a figure of authority such as parents and teachers who are significant in making the way they feel about their academic achievements, followed by their peers. While among lower grade, they tend to feel that no one is significant in influencing their feeling of being successfull or unsuccessfull. They also put some credit to their peers as those who make them feel successful or unsuccessful. Meanwhile, the authority figures such as teachers and parents were placed in positions that are not significant in determining the feeling of successful or unsuccessful that they feel

\section{REFERENCES}

Anwar, Z. 1996. Tes Prestasi. Yogyakarta: Liberty

Barber, J.G. 1985. Competing Accounts of the Learned-Helplessness Effect in Human. Thesis Unpublished. Unviersity of Adelaide.

Blair, J.R. 1972. The effect of differential reinforcement on the discrimination learning of normal and low achieveng middle-class boys. Child Development, 43, 251-252.

Canino, F.J. 1981. Learned-Helplessness Theory: The implication for research in learning disabilities. Journal of Special Education, 18, 471-484

Cullen, J.L. \& Boersma, F.J. 1982. The influence of coping strategies on the manifestation of learned-helplessness.Contemporary Educational Psychology, 7, 346-356.

Dweck, C. 2000. Self-Theories: Their role in motivation, personality and development Philadelphia, PA: Psychology Press.

Dweck, C.S. \& Repucci, N.D. 1972. Learnedhelplessness and reinforcement responsibility in children. Journal of Personality and Social Psychology, 25, 109-116.

Hiroto, D.S. \& Seligman, M.E. 1975. Generality of learned-helplessness in man. Journal of Personality and Social Psychology, 31, 311327.
Holt, I.J. 1980. A preliminary Investigation of Learned-Helplessness in Juvenile Delinquen. Thesis unpubisbhed. Ohio State university.

Jalil, A. Penyebab Prestasi Akademik anak anjlok, Suara Merdeka 6 Maret 2006.

Peterson \& Seligman and Social Psychology. 1984. Causal Explanation as a risk factor for depresion: Theory and Wvidence. Psychological Review, 31, 311-327.

Ramirez, E., Maldonado, A., \& Martos, R. 1992. Attribution modulate immunization agaisnt learned helplessness in human. Journal of Personality and Social Psychology, 62, 139146.

Razeen, M.A.M. 2004. Investigaing Risk for Learned-Helplessness among low academic achiever at International Islamic Univeristy Malaysia: An Exploratory Study. Thesis Unpublished: International Islamic University, Malaysia.

Scales, P.C. \& Roehlkelpartain, E.C. 2003. Boosting students achievement: New research on the Power of Developmenet Assets Search Institute Insights and Evidence, 1, 1-10.

Seligman, M. \& Maier, S. 1967. Failure to escape traumatic shock. Journal of Experimental Psychology, 74, 1-9.

Seligman, M.E.P. 1991. Learned Optimistm. New York: Alfred A. Knopf.

Shields, K. 1997. The Conflict of learned helplessness in motivation. Diunduh.10 Maret 2011dari: Http//ematusov. Soe.udel. edu/final paper pub/_pwfsfp/00000062/html

Stipek, D.E.P. 1988. Motivation to learning. Boston: Allyn and Bacon.

Sundiawan, A. 2006. Prestasi Olimpiade Sains Hanya Kamuflase.

Thantawi. 1997. Kasus Bimbingan dan Konseling. Jakarta Timur: Pamator.

Titscher A. \& Kubinger. 2008. An Innovative Method for Testing Children's AchievementRelated Reaction. School Psychology International, 29, 452-465. 